\title{
O VAMPIRO, UM NÃO MORTO AINDA VIVO
}

\author{
Max Kohn
}

Psicanalista, membro do Espace Analytyque e da Maison de La Mère et de l'Enfant em Paris (Fundação Albert Hartmann,

Sociedade filantrópica).

"Maître de conférence" e orientador de pesquisas na Universidade Paris Diderot.

Tradução Pedro Henrique Bernardes Rondon

RESUMO: O que um vampiro representa? Por que ocupa tal lugar na cultura? O vampiro é um invariante cultural com diferenças culturais. O vivente é um não morto (undead), e o não morto ainda está vivo. Do ponto de vista psicanalítico, qual é, então, essa relação com os dentes e com a mordida que contamina, que faz com que o outro se torne também um vampiro? O vampiro é um bebê que morde e tem um desejo ambivalente de imortalidade. O leite materno é vital como o é o sangue para o vampiro. A brincadeira de mordiscar, para o bebê winnicottiano, conta mais do que a mordida para o bebê kleiniano. O bebê kleiniano é mais próximo do vampiro do que o bebê winnicottiano.

Palavras-chave: Bebê, invariante cultural, mordida, não morto, vampiro.

ABSTRACT: The Vampire, a live undead. What does a vampire represent? Why does he have such a place in the culture? It is a cultural invariant with cultural differences. The living is an undead and the undead is still living. From a psychoanalytical point of view, what is the connection to teeth and to bites that contaminate, and make the other become a vampire? The vampire is a baby that bites and who has an ambivalent desire of immortality. Maternal milk is as vital as blood for the vampire. The game of biting for the Winnicottian baby is more important than the bite for the Kleinian baby. The Kleinian baby is closer to the vampire than the winnicotian baby.

Keywords: Baby, cultural invariant, bite, undead, vampire. 
0 que um vampiro representa? Por que ocupa tal lugar na cultura? Toda uma tradição está em jogo no mito do vampiro. As obras de Stephanie Meyer (2005), Crepúsculo, recentemente adaptadas para o cinema, tiveram grande sucesso de público. O livro de Bram Stocker, Drácula (1897) tornou-se um grande clássico da literatura, mesmo que tenha sido precedido pelo de Marie Nizet (1879). Bram Stocker condensou em seu livro toda uma mitologia, não apenas ocidental, mas, antes, mundial em torno de vampiros. A literatura se apossou dela, o cinema em seguida, contribuindo dessa maneira para o fenômeno mundial. Está em jogo aqui certa imagem do corpo que retoma uma mitologia num momento muito particular da história ocidental. Partindo da análise desse invariante cultural do vampiro, uma “assombração em corpo”, vamos seguir o modelo psicanalítico do bebê que morde, para responder à nossa pergunta de partida acerca da natureza do vampiro.

\section{O VAMPIRO, UM INVARIANTE CULTURAL}

O vampiro é um invariante cultural, como o mostra Claude Lecouteux (2009). É o símbolo da intrusão da morte num universo que a exclui. O vampiro representa a inquietude que nasce de uma ruptura da ordem, de uma fissura, essencialmente na relação dos mortos com os vivos. É o que Lecouteux estuda, a partir dos tratados do século XVIII que analisam histórias de vampiros, intituladas de memora, isto é, relatos dignos de passar à posteridade, em razão de seu caráter excepcional. A lenda não é comparável ao conto enraizado na vida cotidiana. A lenda se refere a um sistema de crenças, explica ele. É precisamente por essa razão que é preciso analisar o mito do vampiro como invariante cultural.

O saber vampirológico é, por assim dizer, teorizado no livro de Bram Stocker, se explicando pelo entusiasmo pelos vampiros nessa época. A explicação da não decomposição dos vampiros é um enigma que o mito busca resolver. Os vampiros transgridem todas as regras da natureza, e põem novamente em questão as noções de vida e de morte. Primeiro, são as almas do outro mundo e, na Antiguidade clássica, toda interrupção antecipada da vida tem consequências perigosas para o indivíduo e para os demais viventes.

O homem deve cumprir seu destino, viver o tempo que lhe é atribuído pelos deuses, de outro modo não há falecimento, isto é, não há passagem para o outro lado. A morte é um rito de passagem. Uma pessoa que não viveu até o termo que lhe foi prescrito não pode passar, e fica bloqueado entre aqui e além. Existem, portanto, más mortes, e as boas mortes são uma dádiva dos deuses. Os defuntos formam uma comunidade próxima da dos viventes.

O vampiro é um membro de uma família de almas do outro mundo específicas. Há uma tradição do vampiro, há toda uma mitologia em torno desse tema, 
através da ideia de que há seres que podem chupar o sangue de pessoas vivas normais, e torná-las vampiros por contágio. Nessa mitologia já encontramos a ideia de um contágio possível pelo contato da sucção. De que corpo se trata? O vampiro é homem ou mulher, tem dentes compridos e brancos, e sua aparência é antes de palidez. Sai à noite de seu caixão e/ou de seu sono para tentar morder o pescoço de suas vítimas e lhes chupar o sangue, tornando-as vampiros, por sua vez. É bem visível aí uma dimensão diabólica. Existem diversas maneiras de sair daí. Trata-se de acabar com os corpos deles. Quando estão em seus caixões, é preciso lhes enfiar uma estaca de madeira no coração, cortar-lhes a cabeça e enchê-la de alho, assim como ao seu corpo. Além disso, é preciso ter à mão um crucifixo.

O nível antropológico é extraordinariamente rico. Historiadores, sociólogos, antropólogos (LECOUTEUX, 2009) estudaram esse assunto. Constata-se que os períodos de aparecimentos e de caça às "almas do outro mundo em corpo" são os mesmos das epidemias de peste na Europa (CHMIEL, 2001). O mito do vampiro aparece no século XVIII, no momento em que a ciência se desenvolve e em que há epidemias de peste. Houve de fato nessa época muitos cadáveres que eram perigosos porque transmitiam uma doença. Quando se faz um histórico desse mito, encontra-se, então, no Ocidente, a peste. Há, também, na história muitos criminosos que cometeram horrores, associados à figura do vampiro. É a ideia de que essas pessoas são não humanas.

O interessante é saber sobre que realidade psíquica se constitui esse mito. O que pensar sobre a dentição, o sangue, a oralidade? Os mitos são construídos sobre a realidade psíquica do sujeito.

O livro de Bram Stocker, Drácula, tornou-se um grande clássico da literatura. Após dez anos de escrito. O próprio Bram Stocker se inspirou na obra de Marie Nizet (1879) que já falava de um vampiro. Se não inventou o mito de Drácula que pode ser encontrado na literatura que o precede, tem o mérito de ter concentrado em sua obra toda uma mitologia esparsa. A tal ponto que é possível dizer que tudo o que surge a seguir sobre o tema dos vampiros no Ocidente saiu de Stocker.

O campo da cultura se define como uma fronteira entre os vivos e os mortos, para o filólogo e filósofo Rudolf Kleinpaul (1989), que Pierre Kaufmann (1974) retoma em seguida a Freud, definindo-o como um sistema específico de símbolos. É preciso que haja uma fronteira estanque. É o significante também que pode tornar uma fronteira mais ou menos porosa ou estanque entre os vivos e os mortos, sem suturar a circulação entre os dois, e é aí que o vampiro aparece. É um significante que reorganiza as relações entre os vivos e os mortos numa cultura. Uma cultura deve poder se certificar de que seus mortos estão verdadeiramente mortos e de que seus viventes estão verdadeiramente vivos. 
O vampiro concentra e canaliza nele, como poder, figura e imagem também, tudo o que há de indeterminação em nós quanto à distinção entre a vida e a morte, todo um vazio entre vida e morte.

Freud fala de uma projeção do desejo de imortalidade. E afirma que o inconsciente ignora o tempo. Ignora a temporalidade. Uma parte de nós ignora, portanto, o tempo, visa à imortalidade e pura e simplesmente recusa a morte. Será que o "retorno em corpo" do vampiro é um retorno a algumas figuras que cristalizam o desejo de imortalidade do inconsciente? É mais complicado do que isso. Porque há o contágio, a oralidade, um perigo de identificação. Nós estaríamos misturados a vampiros na sociedade humana. Há estratégias para erradicá-los, mas as há também para reconhecê-los. Há uma ameaça permanente no seio do mundo humano que é de nos defrontarmos com vampiros que não podemos identificar. Vejamos agora como a psicanálise fala do vampiro.

\section{PSICANÁLISE DO VAMPIRO E O VAMPIRO NA PSICANÁLISE}

A literatura psicanalítica relacionada com os vampiros não é muito importante. É possível citar Karl Abraham (1965) que descreve a fase de sucção pré-ambivalente e evidentemente ligada ao momento da sucção no vampirismo. Em seu ensaio Le cauchemar, Ernest Jones $(1931,2002)$ destaca que o vampiro é um símbolo das pulsões inconscientes e da defesa psíquica. O mito tem a ver com os desejos infantis, em particular desejos incestuosos diante do morto. O medo da alma do outro mundo é o medo dos viventes de ver determinados conteúdos inconscientes recalcados voltarem à consciência, o que, segundo Jones, explica por que é frequente que o vampiro venha assombrar parentes próximos.

Para Pérel Wilgowicz (2000), o modelo do vampirismo é também o de uma análise em que dois seres estão ligados um ao outro na impossibilidade de morrer como de nascer. Um opaco ao outro Um impenetrável ao outro, e o segundo exangue; um bebe na transfusão sua sobrevivência, o outro se esvazia de sua essência vital. Esse modelo de transfusão concebido a partir do vampirismo é o próprio modelo de uma análise. Este é um momento quase inexplorado.

Wilgowicz (2000) pensa que o mito de vampiro, "alma do outro mundo em corpo”, nem morto nem vivo, e suas variantes literárias e artísticas, se prestam a esclarecer aspectos clínicos e metapsicológicos aquém das problemáticas edipianas e narcísicas. Um vampirismo psíquico pode ser revelado nas patologias narcísicas, borderline, ou psicossomáticas está em ação particularmente nas patologias do luto e pós-traumáticas. Irrepresentável, ante e antinarcísico, o vampirismo associa uma tendência à indistinção sujeito/objeto, uma imprecisão de limites temporoespaciais, a circulação umbilical de um fluxo sanguíneo de um ao outro dos parceiros no interior de uma pele comum. Negando origem, nascimento e 
mortalidade, forçando em tensão infanticida e matricida/parricida, o vampirismo encadeia as gerações no processo vampiresco de uma "precedência" muda da linhagem anterior, que entrava a subjetivação. É pré-narcísico, o arcaico absoluto: é o caos onde não há ato de palavra que nomeia e separa. O vampyro de Pérel Wilgowicz designa a “alma do outro mundo em corpo”. É um vampiro que é um não morto não vivo. O Vampyro designa também o vampiro vampirizante num laço indissociável com o vampirizado: o processo vampiresco do qual o vampiro é o agente e o vampirizado é o objeto.

André Green (1983) tem a ideia de que uma relação vampiresca liga a imago da mãe fálica àquilo que é a criança. O vampirismo psíquico se refere às patologias do narcisismo nas estruturas ditas clínicas. O vampirismo ocupa o lado de cá do espelho: não é figurável, nem representável, sem reflexo, sem sombra, sem imagem num universo sem tempo e sem espaço, fora do recalcamento. É a imortalidade de um narcisismo primário absoluto que é infiltrado de pulsões de morte.

Por seu lado, Donald D. Winnicott (1965) evocou a transferência vampirizante de determinados pacientes que exigem uma longa elaboração da separação. Willy Baranger $(1985,1999)$ descreve diversas espécies de mortos vivos em estados depressivos.

O tema do vampirismo atravessa toda a psicopatologia e assim o encontramos em Jean-Claude Sempé (1976, 1978). Alain Roger (1985) aborda o vampirismo no enquadramento da perversão e do fetichismo. Dominique Pérard (1985), junto de crianças dialisadas, fala de uma paciente ligada a uma "máquina-vampira" em relação com uma avó vampirizante. É preciso citar ainda os trabalhos de Prudent-Bayle (1986) e de Jean-Claude Aguerre (1993, 1996, 1997). Os de Nicolas Abraham e Maria Torok (ABRAHAM \& TOROK, 1987) também são importantes: sobre o luto, a cripta, o fantasma, a obsessão. Foi isso que estimulou Pérel Wilgowicz em direção ao vampirismo. Ela se pergunta na ocorrência se não haverá uma identificação com o vampiro na identificação endocríptica deduzida por Abraham e Torok. Essa identificação vampiresca que forra a membrana críptica seria reatualizada no analista graças à contratransferência. O analista modularia afetos que não são verbalizados, seja do analisando criança, seja dessas imagos, para permitir a abertura da cripta, a transformação da incorporação do objeto num processo de introjeção.

\section{O VAMPIRO É UM BEBÊ QUE MORDE}

Do ponto de vista psicanalítico, qual é então a relação com os dentes e a mordida que contamina, que faz com que o outro também se torne vampiro? 
“O beijo faz de vós um não morto”, diz Van Helsing ao Doutor Seward em Drácula. O beijo aqui é um desencadeador, uma vez que é algo propriamente humano. Isso interroga acerca da significação do beijo nas práticas humanas. O beijo é muito antropomórfico.

É um mito que encontra uma fantasia universal que é de que, para sobreviver, o lactente deve praticar a sucção. O beijo no homem é algo cultural muito construído que, portanto, não tem equivalente no animal. Quando o bebê suga o seio de sua mãe, isso se situa, evidentemente, mais no pulsional do que no cultural. Freud, a esse propósito, fala de pulsão oral. O beijo é um objeto de civilização. O beijo do vampiro é tudo, menos sucção. Aliás, no cinema o beijo é uma cena sabiamente construída. É o momento do filme em que um indivíduo vai passar do estado humano ao estado de vampiro. O vampiro está, por fim, de preferência do lado da mordida do que do beijo. O vampiro é um operador da passagem entre natureza e cultura em nós. A mordida do vampiro não é terrível apenas para aquele que a recebe, mas também para as futuras presas deste último. É um ato com consequências múltiplas e terríveis.

É difícil associar a mordida do vampiro à do canibalismo, porque o próprio vampiro não come. É, entretanto, possível ver aí uma pista de reflexão como Lévi-Strauss (2000) lembra, em toda sociedade humana há um risco de comportamento predatório. A civilização é o interdito do incesto, mas também o interdito do canibalismo. Mas, ao mesmo tempo, o horizonte permanente de uma civilização é a possibilidade de ação predatória.

Toda a arte do beijo faz parte de um painel da sedução do apaixonado.

Van Helsing explica: "se a vítima da mordida morre, então os furinhos de seu pescoço cicatrizam”. Sucção, beijo e mordida por si mesmos, não produzem nenhum efeito de periculosidade. Mas no inconsciente esse ato possui um lado perigoso mais desenvolvido. É porque o erotismo se mistura aí, e que a sexualidade não está distante. As construções sociais em torno do beijo vêm afirmar que é possível ir até o canibalismo.

No registro da arte erótica, o beijo pode marcar, mas vai se apagar. Na realidade humana, o vestígio que isso deixa se apaga. No mundo dos vampiros, é preciso que a vítima morra para que o vestígio do beijo se apague, o que não é o caso no ser humano. O que é morder alguém? É marcá-lo.

As crianças que não vão bem porque ninguém as reconhece começam a morder as outras crianças. Quando os pais fracassam de todo, os bebês vão se dirigir a outros bebês mordendo-os. A mordida é uma palavra: todos os sintomas são palavras.

Com o vampiro estamos ao mesmo tempo do lado de cá do estádio do espelho, da constituição da palavra, da mordida da linguagem sobre nós. A ordem simbólica da qual a linguagem faz parte tanto quanto as línguas, para retomar o 
que Lacan (1966) dizia, exerce uma mordida que preexiste a nós como sujeitos. E é possível dizer que o vampiro é um bebê intemporal muito grande, sem nome, constituindo um fardo de carne atravessado por fluidos vitais e pulsionais. Pode ser perigoso para o adulto, porque pode matar a mãe e as pessoas que estão à sua volta a poder de desejos ou necessidades vitais.

O bebê é alguém que morde o seio materno. Melanie Klein (1968) fala da relação da criança com a agressividade. Há também agressividade e sadismo no próprio fato de mamar: de certa maneira, é uma devoração. O que a psicanálise mostra é que há, num momento ou outro, uma fusão entre o seio e o bebê. Winnicott (1975) é um dos que falam disso com mais clareza: o bebê encontra sua mãe, mas acredita que a cria. O bebê é onipotente de tal maneira que o seio materno foi ele quem o criou. E depois, um dia, ele se dá conta de que isso não é verdade. Há em comum com o vampiro o aspecto agressivo, sádico, oral, fusional e contaminante.

É, portanto, uma situação anterior ao desmame. O mito do vampiro conta alguma coisa desse arcaico. Aliás, o momento do aparecimento dos dentes de leite é um momento muito difícil para o bebê. Os dentes podem ser perigosos, mas podem, também, ser ameaçados. O bebê kleiniano é mais próximo do vampiro do que o bebê winnicottiano. Para o bebê kleiniano, a mordida é fundamental, assim como os primeiros objetos, ao passo que para o bebê winnicottiano é a brincadeira que conta, e não os primeiros objetos. A brincadeira de mordiscar para o bebê winnicottiano conta mais do que a mordida para o bebê kleiniano.

Na problemática geral “o que é um vampiro?”, duas hipóteses caminham lado a lado desde o início: um invariante cultural e depois um invariante da psicanálise e que é o bebê. A primeira das experiências do lactente é a mamada. E ainda que não se trate da mãe, mas de uma mamadeira, encontramos a mordida. E quando vemos os filmes de vampiros e que lemos a literatura a esse propósito, temos a impressão de alguma coisa muito arcaica que está do lado da mordida, do lado da oralidade, e não está, de maneira alguma, numa sexualidade genital. Há ao mesmo tempo todo esse imaginário à volta do sangue: o leite é substituído pelo sangue. Isso produz, na realidade, os mesmos efeitos se se tratasse de leite: isto é, uma impressão de satisfação. Exceto que não é mais uma fonte de vida, mas uma fonte de morte e que é, mais ainda, de imortalidade. Isso evoca as metamorfoses do corpo da criancinha em sua história vindoura: de que maneira ela passa, como diria Freud, de um estádio a outro.

O mito do vampiro comporta um invariante cultural e uma fantasia que se refere também ao beijo. Eros, o deus grego do amor reanima Psique com um beijo. Já estamos aí do lado da vida. Ele pode igualmente frustrar os sortilégios transformando os sapos em príncipe encantado e insuflando a vida nas princesas 
adormecidas (CAHEN, 1997). Na Bíblia, o beijo é associado à criação do homem, à transmissão da alma: Deus cria Adão por um sopro, o que os cabalistas traduzem por um beijo. O beijo, explicam-nos, atenua as pulsões sexuais sem ter que passar ao ato. In utero o feto espontaneamente leva o polegar à boca. Exceto que neste caso o imaginário faz com que esta já não seja mais uma fonte de vida, mas uma fonte de morte, de renascimento e metamorfose no vampirismo.

Mostramos neste artigo a importância do vampiro como invariante cultural com diferenças culturais, que na perspectiva psicanalítica pode ser associado ao bebê que morde. O vampiro é um invariante cultural com diferenças culturais. O vivo é um não morto (undead) e o não morto ainda está vivo. De um ponto de vista psicanalítico qual é, então, a relação com os dentes e a mordida que contamina, que faz com que o outro se torne também vampiro? O vampiro é um bebê que morde e que tem um desejo ambivalente de imortalidade. O leite materno é vital como o é o sangue para o vampiro. A brincadeira de mordiscar para o bebê winnicottiano conta mais do que a mordida para o bebê kleiniano. O bebê kleiniano é mais próximo do vampiro do que o bebê winnicottiano.

Recebido em 7/7/2011. Aprovado em 17/8/2011.

\section{REFERÊNCIĀS}

ABRAHAM, K. (1965) Euvres complètes. Trad. I. Barande. Paris, Payot. AGUERRE, J.-C. (1996) “Lecture”. In: Le Vampire, d'après Lord Byron. Polidori (Arles), Actes Sud. (1997) “Si la chair n’était pas faible”, Dracula. Paris: Éd. Autrement. . La Naissance du vampirisme au XVIII e siècle, Diplôme d’Études supérieures de l'Institut polytechnique de Philosophie, Université de Paris VIII, Bibliothèque nationale.

(1993) “Résistance de la chair, destitution de l’âme". In: Les Vampires. Colloque de Cerisy, Albin Michel (Cahiers de l'Hermétisme)

BARANGER, W. (1985) Structure des objets dans le deuil et les états dépressifs, Revue Belge de Psychanalyse, n.6, p.97-111.

(1999) Position et objet dans l'œuvre de Mélanie Klein. Trad. D. Faugeras. Toulouse: Érès, La Maison jaune.

CAHEN, G. (1997) Le Baiser. Premières leçons d'amour. Paris: Autrement.

CHMIEL, D. (2001) Les Vampires et le souterrain, Sociétés 3 (n.73), p.21-28.

GREEN, A. (1983) Narcissisme de vie, narcissisme de mort. Paris: Minuit.

JONES, E. (1931, 2002) Le Cauchemar. Paris: Payot.

KAUfMANN, P. (1974) Psychanalyse et théorie de la culture. Paris: DenoëlGonthier.

KLEIN, M. (1998) Essais de psychanalyse 1921-1945. Paris: Payot. 
KLEINPAUL, R. (1898) Die Lebendigen und die Toten in Volksglauben, Religion und Sage. Leipzig: G.J. Göschen'sche Verlagshandlung.

LACAN, J. (1966) Ecrits. Paris: Seuil.

LÉVI-STRAUSS, Cl. (2000) "L’apologue des amibes", In: JOMARD, J-L.; TERRAY, E.; XANTHAKOU, M. (Eds.) En substances : textes pour Françoise Héritier. Paris: Fayard, p. 493-496.

LECOUTEUX, Cl. (2009) Histoire des vampires: Autopsie d'un mythe. Paris: Imago.

MEYER, S. (2005) Fascination. Paris: Twilight (Coleção Black Moon) (2006) Tentation. Paris: Twilight. (Coleção Black Moon) (2007) Hésitation. Paris: Twilight. (Coleção Black Moon) (2008) Révélation. Paris: Twilight. (Coleção Black Moon)

NIZET, M. (1879-2004) Le Capitaine Vampire. In: CAZACU M., Dracula. Paris: Allandier.

PÉRARD, D. (1985) La Grand-mère machine-vampire de Marie-Sophie. Perspectives psychiatriques, n.104, p.386-397.

PRUDENT-BAYLE, A. (1986) “Le Vampirisme: fantasme et réalité”, Mémoire de maîtrise de psychologie clinique, Universidade de Dijon.

ROGER, A. (1985) Hérésies du désir. Freud, Dracula, Dali. Seyssel: Champ Vallon.

SEMPÉ, J.-C. (1976) “Le Vampirialisme, ou le pouvoir de l'antisexe”. In: Sexualité et pouvoir. (1978) “Un conte psychanalytique vampirique”, Études freudiennes, A 3/14.

STOCKER, B. (1897-2006) Dracula. Londres: Penguin Books. (1897-2010) Dracula. Trad. de Jacques Sergent. Paris: Camion noir.

TESTART, A. (1991) Des mythes et des croyances: esquisse d'une théorie générale. Paris: Maison des Sciences de l'Homme, p.195-196.

TOROK, M. (1987) L’Écorce et le noyau, em colaboração com N. Abraham. Paris: Aubier Flammarion.

WILGOWICZ, P. (2000) Le Vampirisme. De la Dame Blanche au Golem. Essai sur la pulsion de mort et sur l'irreprésentable. Lyon: Césura (Coleção Psychanalyse d'autres horizons)

WINNICOTT, D. W. (1965-1989) Processus de maturation chez l'enfant. Paris: Payot.

(1975) Jeu et réalité, l'espace potentiel. Paris: Gallimard (Playing and Reality, 1971), reeditado em fólio, 2004.

Max Kohn

maxkohn@wanadoo.fr 